\title{
Research on the Development of Industrial Parks in China and Suggestions for Future Policies
}

\author{
Tianjiao Yi \\ International Business School of Shannxi Normal University \\ Xi'an, Shannxi, China
}

\begin{abstract}
Based on the former research into industrial parks at home and abroad, in this paper, we define the concept of industrial parks, and classify some of the existing industrial parks in China into different types. With the classical economics theory, we analyze and explain the intrinsic economic motivation for the formation of the industry parks. Further study shows that the development of industrial parks in China can be divided into four stages, and then we present the current status of the development of two typical kinds of industrial parks in China. Finally, conclusions are drawn, and policy suggestions to enhance the competitiveness of industrial parks in the future are given.
\end{abstract}

Keywords-Types of Industrial Parks; Formation Mechanism; Evolutionary Stages; Policy Suggestions

\section{THE CONCEPT AND TYPE OF THE INDUSTRIAL PARK}

Industrial park is essentially a form of industrial clusters, considering the definitions of industrial park from different angles, in this article, we define industrial park as follow: in a country or a region, industrial enterprises from the same field gathered into cluster through the government intervention or spontaneous formation, this area usually has complete infrastructure and good social environment, with high intensification degree and distinctive characteristics. There are obvious industry association between the enterprise, which is an effective way to promote regional economic development. We divide the industrial parks into five main categories. Industrial park: industrial park is an agglomeration of many industrial enterprises, usually with a larger development area, surrounded by supporting infrastructure and having certain location advantages. Industrial parks set series of standards and limits in planning, land utilization and entry criteria.

Economic and technological development zone: economic and technological development zone appeared during the period of transformation in economic system of our country which attracts companies with preferential policies, good environment business, foreign capital and advanced technology. The product is mainly export-oriented and the enterprises welcome foreign investment. The dominant industry is mostly modern manufacturing industry.

High-tech industrial development zone: hi-tech industry development zone is led by the knowledge-intensive and technology-intensive industry, this kind of industrial park is set up for the purpose to develop new technology, besides enterprises, it includes universities and research institutions, so it can promote the commercialization of scientific achievements but also speed up the prosses of the transition.
Though have different name all around the world, but hightech industrial development zones are generally based on intellectual resources, aiming at the development of new industries, facilitating the combination of scientific research, education and production.

Characteristic industrial park: the leading industry in the characteristic industrial park relies on the unique local resources, the industrial park can give full play to the spreading effect to lead regional economic growth. This kind of industrial parks including logistics parks, cultural creative industry clusters, ecological agriculture park.

Other types: in addition to the above types of parks, there are export processing parks, free trade zones, bonded areas, border economic cooperation zones, etc.

\section{THEORETICAL BASIS}

Seeking efficient and sustainable development model has been one of the main themes of industrial development ever since the industrial revolution. In the middle of the 19th century, the industrial activity started to centralize in a certain area, isolated from residential areas and agricultural areas. These industrial activity areas gradually known as industrial park. In the end of the 19th century, the British economist Alfred Marshall put forward the concept of "industrial cluster" to explain this phenomenon for the first time. Later in the 20th century, economists form all over the world advanced the theory of industrial clusters. Michael E.Porter put forward the "diamond model" to demonstrate industrial clusters competitiveness, and discussed how cluster promotes the competitiveness. Industrial clusters are very important to stimulate the growth of regional economy, also the crucial factors in the process of industrialization. Industry cluster theory is the theoretical basis for the development of industrial park.

Industrial park enhances the overall competitive advantage promote the production elements concentration and industrial upgrade by gathering the enterprises in the same industry, related producer services and supporting enterprises. It generates the effect in economies of scale, reduces the management and transaction costs, strengthens the connection of different enterprises in the industry, promote the common $\mathrm{R} \& \mathrm{D}$, knowledge diffusion, human capital flows. On the other hand, the industrial park can create unique brand effect to exert its advantages in international competition, purchasing, marketing, and in the negotiations with the government. 
Compared with other areas, industrial parks are able to attract more investment, the land utilization is more intensive, can maximize the development benefit. At the same time, industrial parks can produce synergies in environmental protection. Government-led development industrial parks generally use a variety of reward, taxation and financing policies to promote and attract investment. And furthermore, through every link of industry associations, the industrial parks derive a batch of affiliated enterprise with collaboration relationship and expand itself. The large enterprises are as the core of the clusters, they lead the development of small and medium-sized enterprises in both upstream and downstream

\section{DEVELOPMENT TRAJECTORY AND CURRENT STATUS}

\section{A. Development Track of the Industrial Parks}

The development of domestic industrial parks is closely related to the construction and development of economic and technological development zones after the reform and opening up. In 1979, the Central Committee of the Communist Party of China decided to establish the special economic zones in Shenzhen, Zhuhai, Shantou, Xiamen. The Shekou industrial zone which covers an area of 2 square kilometers is the first industrial park opening to the outside world in China. In 1984, 14 coastal cities are allowed to designate a region with clear geographical boundaries in order to establish economic and technological development zones. In 1988, China established its first high-tech industrial development zone-Beijing new technology industrial experimental development zone. In the same year, Caohejing new technology development zone was built. In 1992, a large number of provincial capitals and cities along the Changjiang river and the border began to build a national high-tech industrial development zone. Since the reform and opening up, the development of China's industrial parks can be divided into the following four stages:

Initial development stage (1984-1991), most of the industrial parks were special economic zones, government used preferential policies, normally in tax, land, human resource, finance and other aspects to attract domestic and foreign capital and promote industrial development and technological progress.

Rapid development stage (1992-2002), rapid development stage in addition to the support policies mentioned before, government mainly improved the management system, the promotion of modern service industry, industry clustering, structure optimization, infrastructure construction, etc. In terms of the park management system, due to the weakening of policy advantages, the government proposes that all industrial parks should promote industrial innovation, technological innovation, system innovation and investment innovation. At the same time, the policies of strict examination, sorting out and approval of all kinds of developing zone were issued. And the state encouraged foreign investment to establish industrial parks of agriculture, tourism and high technology. In addition, more attention was paid to industrial cluster rather than geographical centralization. The government gradually focused on promotion of industrial chain. It is worth mentioning that in this phase the state attach importance to the land intensive utilization and the land-losing farmers' compensation system.

Stable development stage (2003-2008), at this stage, the innovation, industrialization and development of new technology were highlighted, and the government started to realize the cooperation issues between industrial parks. As for innovation policy, the state offered support and encouraged the introduction-absorption-innovation process to strengthen the enterprises' capacity for independent innovation and the core competitiveness. The interactive development and organic fusion of modern manufacturing industry and service industry were effectively promoted, the service outsourcing was required to upgrade the industrial structure. In addition, to ease the contradiction between supply and demand of land and to protect arable land, China implemented the most stringent land conservation policy.

Upgrading and development stage (from 2009 to now), during this stage, the development of national industrial parks was more diversified. In addition to the continuation of the previous policies, green parks were emphasized, the state required the parks to change the traditional development mode of high pollution, high energy consumption and terminal management, to implement the certification of international environmental management system. The government began focus on the construction of the parks' soft environment, which involved policies such as innovation and entrepreneurship atmosphere, harmonious park, employment and social insurance. In regional cooperation and coordination, a series of expansion strategies of national industrial park were implemented in Midwest, because of the unbalanced development. In this stage, the incentive mechanism of share ownership, disposition of scientific and technological achievements, the scientific research project funds management were successively implemented. At the same time, the industrial parks began to pay attention to the people's well-being of the development zone.

\section{B. Current Status of Industrial Parks}

Considering the data availability and the output value proportion, we take economic and technological development zones and high-tech industrial development zone for instance, to analysis of current situation of the development of domestic industrial park. In 2016, there were 365 national economic zones and high-tech zones in China. The total GDP of the two types of national parks was 17094.6 billion yuan, which reached $22.97 \%$ of the national GDP. The total tax paid by the two types of national parks was 2932.7 billion yuan, which was 25.31 percent of the national tax. The two types of national parks generated 5525.4 billion yuan in foreign exchange from exports, accounting for about $40 \%$ of China's foreign exchange from exports. Faced with the difficult recovery of the world economy, the two types of national parks showed a steady rise, and the relevant economic indicators of the high-tech zone have increased slightly more than that of the economic zone. In 2016, the GDP of the two types of national parks increased by $8 \%$, higher than the national GDP growth rate $(6.7 \%)$. Taxes paid in the two types of national parks increased $7.4 \%$, higher than the national rate of $4.8 \%$. The export earnings of the two types of national 
parks dropped $2.1 \%$ compared with the previous year, roughly the same as that of the whole country.

On December 3, 2017, development Institute of Tongji University released "2017 China industrial parks sustainable development blue book". The "blue book" scored and ranked the two types of industrial parks from these 5 indicators below: social development, public services, industrial cooperation, innovation and economic development. According to the results, Zhongguancun national innovation demonstration zone, Zhangjiang national independent innovation demonstration zone, Suzhou industrial park, Tianjin economic and technological development zone, Guangzhou economic and technological development zone, Wuhan east lake national independent innovation demonstration area and the Qingdao economic and technological development zone were the industrial parks which remained in the top 10 for 5 years. In 2016, there were 64 industrial parks in the east, 21 in the middle and 15 in the west. The number of developed provinces and cities in the top 100 industrial parks occupied an absolute advantage, and the number of top 100 industrial parks in Jiangsu province had the most of the industrial parks in the list.

\section{Policy SugGestions}

(1) Avoiding homogenization, lack of industrial chains and excessive competition, the industrial parks need to seize the opportunity to create unique competitive advantages and build the brand value. At present, many industrial parks in China are still the processing and manufacturing parks with resource-intensive and labor-intensive. Most enterprises with high energy consumption and heavy pollution are in low end of the value chain. To solve this problem, it is very important to plan the industrial park scientifically and explore the profit model. Based on local resource differences, we should vigorously support leading industries in the region, promote "City-Industry Integration", and develop modern manufacturing and producer services to promote adjustment and update of industrial structure.

(2) With market-oriented, clear positioning and accurate connection of the industrial parks, we need to conduct indepth market research, from nation macroeconomic policies, location characteristics, industrial bases, competitive environment, and demand conditions. We should accurately locate the projects of the industrial parks and increase the occupancy rate of enterprises. At the same time, we should make great efforts to complete the infrastructure construction, strengthen the investment promotion and capital introduction, logistics and other supporting industries, pay attention to the development of small, medium and micro enterprises in the park, solve the problem of financing difficulties for SMEs (Small and Medium Enterprises) and expand financing channels.

(3) Balanced development, comprehensive promotion and key breakthroughs is the most important work to do. The industrial park needs to develop and construct many areas. The government and developers must coordinate the effective use of external infrastructure and the orderly construction of internal supporting facilities, popularize the Public-PrivatePartnership model.

(4) Promoting R\&D and innovation as the core competitiveness of the industrial parks is the first priority. To achieve the sustainable development of the park, the enterprises must keep improving innovation and $R \& D$ capabilities. Through the establishment of R\&D platform between university and enterprise, the joint development mechanism inside the clusters, the effective intellectual property protection, the special human capital flow platform, the industrial parks strengthen the scientific research innovation ability, the clusters can speed up the process of research results into productive forces, promote the formation of the culture of the park innovation, build park soft power.

(5) Local governments need to clearly define their functions, identify their functional orientations, and carry on market-oriented operations. At present, the local government is the builder of the regional investment environment, the supervisor of the market order, the organizer of investment promotion activities, and the leader of project investment cooperation. These roles are formed in the process of transition from planned economy to market economy. Under the condition of weak market factors, low competitiveness of enterprises, and underdeveloped intermediary organizations, it is reasonable for government organizations to invite investment activities and to lead project investment cooperation. But in the long term, the government should fade away from the dominant position of attracting investment as soon as possible, give way to enterprises, and focus on creating a good investment environment and entrepreneurial atmosphere for attracting investment. We also need to establish a coordinated, orderly, standardized, competitive market-oriented investment mechanism, improve the supervision mechanism, strengthen supervision and management by integrating various types of investment resources.

\section{CONCLUSION}

The 21st century is the era of knowledge economy. The growth of the world economy will depend more on the production, dissemination, knowledge and information, the capacity of scientific and technological innovation will become the decisive factor for countries and regions to gain economic competitive advantages. It is a vital mission for China to promote industrial structure adjustment, transform economic growth pattern and enhance independent innovation capability so as to achieve stable economic. Both the new and existing industrial parks should focus on the long-term future, and meet the requirements of strategic transformation. There is no doubt that industrial parks have their own development rules, and it is essential to follow the development trend of industrial parks to make a good long-term development plan. Only in this way can we better combine the actual local condition with the plan, promote the rapid development and cultivate the core competitiveness of the industrial parks. 


\section{ACKNOWLEDGMENT}

First of all, I would like to thank I would like to take this opportunity to express my sincere gratitude to my supervisor, Professor Wang Qinmei from the International business school of Shannxi Normal University. Besides her help with my article, she gave me many advices on the methods of doing research, which is of great value to my future academic career. I am also obliged to other scholars whose lectures have broadened my scope of vision and helped me lay a necessary foundation of my work. I am grateful to all the members and staff in the International business school who have provided me with a lot of help and guidance. Last but not least, I would like to thank all my friends and family members, without their help, I could never finish my research and this article.

\section{REFERENCES}

[1] Commercialization strategies of technology: lessons from Silicon Valley [J]. Jarunee Wonglimpiyarat. The Journal of Technology Transfer. 2010 (2)

[2] The determinants of national innovative capacity [J]. Jeffrey L Furman, Michael E Porter, Scott Stern. Research Policy. 2002 (6)

[3] Location and network effects on innovation success: evidence for UK, German and Irish manufacturing plants [J]. James H. Love, Stephen Roper. Research Policy. 2001 (4)

[4] An Examination of Collaboration and Knowledge Transfer: ChinaSingapore Suzhou Industrial Park [J]. Andrew C.Inkpen, WangPien. Journal of Management Studies. 2006 (4)

[5] Towards Sustainable Cities in China? Two Industrial Parks in the Yangzi Delta. Curien,R,D Lorrain. The international Autun Conference. 2012

[6] Understanding ISO14001 Adoption and Implementation in China. Cushing, K.K.et al. Greening Industries in Newly Industrializing Economies: Asian-style Leapfrogging. 2006

[7] Cities of Jiangnan in Late Imperial China. Johnston, L.C. 1993

[8] Development and application of a keyword-based knowledge map for effective R\&D planning [J]. Byungun Yoon, Sungjoo Lee, Gwanghee Lee. Scientometrics. 2010 (3)

[9] [2]Mapping Korea's national R\&D domain of robot technology by using the co-word analysis $[\mathrm{J}]$. Bangrae Lee, Yong-Il Jeong. Scientometrics. 2008 (1) 